\title{
Alkalizing Nutritional Therapy in the Prevention and Reversal of any Cancerous Condition
}

\begin{abstract}
Due to the evident ineffectiveness of conventional cancer treatments (e.g. chemotherapy and radiation), more efficient alternatives are needed. The potential of Alkaline Nutritional Infusion (ANI) as a legitimate alternative to chemotherapy and radiation is examined. While largely ignored in conventional oncology, the $\mathrm{pH}$ of the interstitial fluids is suggested as paramount in identifying a cancerous condition. It is further suggested that cancer is an over-acidic condition of the body that can be reversed and prevented with alkalizing treatments such as ANI. Full Body Bio-Electro Scan (FBBES) is presented as a noninvasive means to examine body $\mathrm{pH}$ and the presence of cancer. In addition, non-invasive Full-Body Thermography (FBT) and Full-Body Ultrasound (FBU) are presented as a noninvasive means to examine the physiology and the anatomy of the ograns, glands and tissues for inflammation, calcifications, cysts and tumors in the prevention and treatment of any cancerous condition. Finally, Live Blood Analysis (LBA) and Dried Blood Analysis (DBA) are non-invasive hematology tests for evaluating the health of the red and white blood cells and to view inflammatory and malignancy at the cellular level. In contrast to the acidosis caused by conventional cancer treatments, ANI methods such as Intravenous Nutritional Infusion (INI) and Rectal Nutritional Infusion (RNI) provide an alkalizing approach to cancer treatment and prevention.
\end{abstract}

Keywords: Alkaline; Base; Acidic; Acid; pH; Oncology; Cancer; Chemotherapy; Radiation; Treatment; Prevention; Reversal; Conventional; Alternative; Infusion; Interstitial; Blood; Diet; Exercise; Thermograph; Ultrasound; Hematology; Immunity; Bacteria; Yeast; Mold; Infection; Malignancy; Inflammation

\author{
Opinion \\ Volume 2 Issue 1 - 2015 \\ Robert 0 Young ${ }^{1 *}$ and Galina Migalko² \\ ${ }^{1}$ Universal Medical Imaging Group, USA \\ ${ }^{2}$ Medical doctor, non-invasive medical diagnostics, USA \\ *Corresponding author: Robert $\mathrm{O}$ Young, $\mathrm{pH}$ Miracle Inc., \\ 16390 Dia del Sol, Valley Center, California, 92082, USA, \\ Tel: 760751 8321; Email: phmiracleliving@aol.com and \\ Universal Medical Imaging Group, 12410 Burbank Blvd, \\ Valley Village, California, 91607, USA, Tel: 818987 6886; \\ Email: universalmedicalimaging@yahoo.com
}

Received: August 29, 2015 | Published: November 24, 2015

\section{Introduction}

While largely ignored in conventional oncology for decades, intravenous nutritional infusion (INI) and rectal nutritional infusion (RNI) are therapies that play a major key in recovering from and reversing any metabolic, environmental, or dietary caused "dis-ease." But when you visit your conventional doctor for any condition or "dis-ease", he or she will rarely address the patient's lifestyle or diet, besides sometimes shrugging and saying, "Eat better and get more exercise." This is generally stated to the patient without giving any specific recommendations of what to eat, what to drink or how to exercise [1-13].

This general mindset stems from medical schools where a physician may receive only a few hours of nutritional, dietary or physical training in their nutritional, biochemistry or physiology courses on the importance of nutrition, diet and exercise. Then all training, including residency and fellowship is completely pharmaceutical-drug focused [1-13]. Only a select few take the time to be trained and mentored by traditional, integrative or naturopathic physicians that specialize in the prevention and treatment of cancer or other "dis-ease" conditions.

\section{Powerful Insights to Non-Invasive Cancer Treatment}

Alkalizing nutrition, diet and exercise is key in prevention, treatment and recovery, especially with a cancerous condition, because chemotherapy and radiation treatments deplete the nutrients and electron energy right out of the body [14-17]. This is why patients undergoing chemo lose their hair, lose weight and look so gaunt or ill-their bodies are literally starving for electronrich alkalizing nutrition, food, and water while simultaneously loading-up with an acid-rich and toxic diet combined with their associated metabolic waste, such as lactic, uric or acetic acid. In addition, it is important to understand when dietary and metabolic acids are NOT eliminated through the four channels of elimination via urination, defecation, perspiration and respiration, these toxins will eventually buildup in the connective tissues leading to inflammation and ultimately degenerative disease, namely cancer [18-21].

Even though oncology as a whole has ignored intravenous and/ or rectal alkalizing nutritional infusions, fearing that alkalizing nutrients will adversely impact chemotherapy or radiation, they really detour patients from these kinds of supportive and noninvasive treatments. This is in spite of 280 peer-reviewed studies, including 50 human studies involving 8,521 patients that have emerged since the 1970's. 5081 subjects that were given nutrients have shown that supplementing nutrients do not interfere with conventional therapeutic modalities for cancer [22].

Every person has unique dietary and metabolic needs, meaning that telling a patient to open wide and then administer some minerals and vitamins orally will not always do the trick. Some 
people need more sodium or potassium and some may need extra vitamin A or E in their diet, while others may need less. Some patients need more magnesium and others have iron deficiencies due to the poor health in the crypts of the small intestines where stem cells are made for differentiation into new and healthy red blood cells [23].

So what are we left with? The fact is, every cancer patient needs a complete, personalized physiological, anatomical, functional, hematological and nutritional profile if he or she really wants the edge in preventing and removing the acids that cause the inflammation that leads to a cancerous condition [18-21]. Let's explore what this all means and how it can make the difference in a patients survival and improving the quality and quantity of life.

\section{In The Beginning ...}

Life on earth depends on appropriate $\mathrm{pH}$ levels in and around living organisms and cells. Human life requires a tightly controlled $\mathrm{pH}$ level in the serum of about 7.365 (a slightly alkaline range of 7.35 to 7.45 ) to survive [24].

As a comparison, in the past 100 years with increasing industrialization, the $\mathrm{pH}$ or acid/base balance of the ocean has dropped from 8.2 to 8.1 because of increasing $\mathrm{CO} 2$ or carbon monoxide deposition. This has a negative impact on life in the ocean $[25,26]$ and may lead to the collapse of the coral reefs. Why? Because the ocean is using the calcium in the coral to maintain its alkalinity much like the body uses the calcium from the bones to maintain the alkalinity of the intracellular fluids, interstitial fluids and blood fluids [24]. Even the pH of the soil in which plants are grown can have considerable influence on the mineral content of the food we eat (as minerals are used as buffers to maintain $\mathrm{pH}$ ). The ideal $\mathrm{pH}$ of soil for the best overall availability of essential nutrients is between 6 and 7. Acidic soils below pH of 6 may have reduced calcium and magnesium, and soil above $\mathrm{pH} 7$ may result in unavailable iron, manganese, copper and zinc to the plant [27].

When it comes to the $\mathrm{pH}$ and net acid load in the human diet, there has been considerable change from the Neolithic civilization to the present [28]. With the agricultural revolution (last 10,000 years) and even more recently with industrialization (last 200 years), there has been an decrease in potassium (K) compared to sodium ( $\mathrm{Na}$ ) and an increase in chloride compared to bicarbonate found in the diet [29]. The ratio of potassium to sodium has reversed, $\mathrm{K} / \mathrm{Na}$ previously was 10 to 1 whereas the modern diet has a ratio of 1 to 3 [30]. It is generally accepted that agricultural humans today have a diet poor in magnesium and potassium as well as fiber and rich in saturated fat, simple sugars, processed sodium containing aluminum, and processed chloride as compared to the preagricultural period [31]. This results in a diet that may induce dietary acidosis which is mismatched to the genetically determined alkaline nutritional requirements. for maintaining the alkaline design of the body fluids at a $\mathrm{pH}$ of 7.365 to 7.4 [32] With aging, there is a gradual loss of renal acidbase regulatory function and a resultant increase in diet-induced metabolic acidosis while ingesting the modern or Standard American Diet [33].
A low-carbohydrate, high-protein diet with its increased acid or proton/hydrogen load results in very little change in blood chemistry and $\mathrm{pH}$, but many changes in interstitial and urinary $\mathrm{pH}$ chemistry: Urinary and interstitial fluid sodium and magnesium levels, urinary citrate and $\mathrm{pH}$ are decreased; urinary calcium, potassium, undissociated uric acid, and phosphates are increased. All of these result in an increased risk for metabolic tissue acidosis, bone loss, and an increase in blood, breast, brain, liver, gallbladder, pancreas, prostate, uterus, and kidney stones [34]. The reason for the increase in stones throughout the body is to buffer the increase of dietary and metabolic acids found throughout the fluids of the body. The increase of stones is the direct result of an increase of dietary and/or metabolic acid-load which, if not corrected, can lead to a cancerous condition in those specific areas [35].

\section{Alkalinity and Chemotherapy in the Treatment of Cancer}

The effectiveness of chemotherapeutic agents is markedly influenced by the $\mathrm{pH}$ or the acid-base chemistry of the body. Numerous agents such as epirubicin and adriamycin require an alkaline media to be more effective. Others, such as cisplatin, mitomycin $\mathrm{C}$, and thiotepa, are more cytotoxic in an acid media [36]. Cell death correlates with acidosis and intracellular $\mathrm{pH}$ shifts higher (more alkaline) after chemotherapy may reflect response to chemotherapy [37]. I have noted with many of my patients that inducing metabolic alkalosis may be useful in enhancing chemotherapy and/or radiotherapy regimes by using alkalizing intravenous or rectal mineral and vitamin infusion therapy of sodium bicarbonate, carbicab, and furosemide [38]. In addition, extracellular alkalinization with mineral salts such as sodium and potassium bicarbonate may result in improvements in the effectiveness of chemotherapy [39].

\section{Alkalizing Nutrition, the Immune System and how together they Fight Cancer}

In the 1880's, Louis Pasteur published his work on cellular aerobic respiration and glycolysis [40,41]. In 1931, Otto Warburg won the Nobel Prize for his work on the metabolism of tumors and the respiration of cells, which was later summarized in his 1956 paper, On the Origin of Cancer Cells. His work on cancer expanded upon Pasteur's findings and described respiratory insufficiency and a cellular metabolism of glucose fermentation increasing metabolic acidosis as the primary trigger for cancer progression [40].

Warburg's conclusions on cancer were much discussed in scientific circles, as they are academically elegant, but were not accepted by most members of the scientific community engaged in cancer research. Most cancer researchers in the late 1950's believed that the anaerobic metabolism of cancer cells and their accompanying output of lactic acid was a side effect or an adjunct effect of cancer, not a cause. Cancer research since the 1960's has focused primarily on genetic aberrations as causative for cancer, and has ignored the body of research on acidic $\mathrm{pH}$ as the cause of cancer and its implications for therapeutic approaches [41]. 
Warburg's work was a catalyst for yet another research effort on the nature of cancerous cells, beginning in the 1930's. A. Keith Brewer, PhD (physicist) performed experiments on the relationship between energized, oxygenated cell membrane and elemental uptake, versus cellular membranes in an unenergized state such as cancerous acidic cells exhibit. He wrote a number of papers discussing the cellular mechanisms of cancerous cells and the changes in metabolism induced or indicated by the lack of or presence of oxygen in combination with other elements, particularly potassium and calcium. He noted that cancerous cells share one characteristic no matter what type of cancer: they have lost their alkaline pH control mechanism [42]

Brewer's conclusion regarding cancer was that by changing the $\mathrm{pH}$ of the fluids that surround cancerous cells above 7.5 to a $\mathrm{pH}$ of 8 or above, they will cease to function as they need an acidic, anaerobic environment to thrive. In other words, he proposed that cancerous cells will die if they can be pushed into an alkaline, oxygenated state [42].

Briefly, let's review: with the alternative understanding that cancer is an acidic condition of the body fluids that affect the body cells, the word cancer should be used as an adjective rather than a noun. Based upon my own clinical research, cancer is what happens to normal (i.e. healthy) cells that reside in a toxic acidic environment. Simply put, cancer is an acidic metabolic or dietary waste, like lactic acid that can potentially spoil healthy cells. Healthy cells are affected by their environment which can activate protective genes [43]. If the acidic internal environment or fluids of the body are not returned to its original alkaline state this will cause mutations or fermentation of the body cells and the lactic acids from these spoiling or rotting cells will spoil other cells, just like one domino tipping over another domino leading to a cancerous condition [40-46].

The reason the body can have trouble fighting or buffering the acids that cause a cancerous condition varies; in part, it has do with protecting the alkaline design of the body fluids at a $\mathrm{pH}$ of 7.365, the health of the white blood cells and the body's ability to neutralize metabolic and/or dietary acidic waste that has not been properly removed via the four channels of eliminationurination, defection, perspiration, and respiration [44-46].

Poor circulation, elimination, and alkaline nutrition leads to a build-up of acidic waste and poor immune defense (the janitors of the blood and interstitial fluids to maintain internal cleanliness by picking up cellular debris or small bacteria and/or yeast), which can increase the number of cancerous cells as one spoiled or rotting cell spoils another, much like one rotten apple will spoil a bushel of healthy apples creating an acidic microenvironment that creates more and more rotten apples or cancerous cells that would be resistant to any conventional acidic treatment [44-46].

Now, the most commonly accepted forms of cancer treatment are chemotherapy and radiation therapy. These acidic drugs and ionizing radiation will systemically destroy already acidic cancerous cells, but they may also turn healthy blood and body cells into cancerous cells. This will create an immediate response from the body to produce and release alkalizing compounds, such as sodium bicarbonate to buffer the increased amounts of acidic waste draining the body of essential nutrients, and critically paralyzing the white blood cells, making them inactive and ineffective in buffering and removing cellular metabolic waste. During these acidic conventional treatments, the immune system is essentially obliterated, which can lead to metastasis while not even affecting the primary site of the original cancerous condition [47]. According to a medical researcher, Steve Gullans, Ph.D, only $30 \%$ of people respond to chemotherapy or radiation, leaving $70 \%$ unresponsive [48]. In addition, the data is clear that after initial chemotherapy fails, as many as $95 \%$ of cancer patients will not respond to the next suggested chemotherapy drug recommended by conventional methods [49]. It is also important to understand that conventional chemotherapy and radiation treatments for cancer are NOT a cure for cancer [50]. The National Confidential Enquiry into Patient Outcome and Death (NCEPOD) found that more than four in 10 patients who received chemotherapy toward the end of life experienced potentially fatal effects! And after reviewing data from over 600 cancer patients who died within 30 days of receiving treatment, it was found that chemotherapy hastened or caused death in 27 percent of cases. "The majority of the cancer patients in this country die because of chemotherapy, which does not cure breast, colon or lung cancer. This has been documented for over a decade and nevertheless doctors still utilize chemotherapy to fight these tumors," said Dr. Allen Levin, MD, author of The Healing of Cancer.

Despite its reputation as the gold-standard cancer treatment, chemotherapy has an average 5-year survival success rate of just over 2 percent for all cancers, according to a study published in the journal Clinical Oncology in December 2004 [47].

Truly, the alkaline buffering system (e.g. the stomach is the main alkalizing organ and responsible to maintain alkalinity of the blood, tissues and organs by producing and secreting sodium bicarbonate on dietary, metabolic, respiratory and environmental acids), which releases antioxidants to buffer increased acidic toxic waste build-up, is the first and last defense against a cancerous condition [51]. If alkalizing nutrition is ignored in the prevention and treatments of cancer, as it has been by conventional oncology for decades, how can a full recovery or at least a satisfactory quality of life be expected? Some oncology groups such as Cancer Centers of America, Huntsman Cancer Institute and MD Anderson Cancer Center have improved by offering in-house nutritionists and Naturopathic Doctors, but oral supplementation is insufficient in reversing a cancerous condition.

Analogously, it would be like trying to take out a forest fire with a squirt gun. Or, like treating a fish in a polluted pond without changing or cleaning the water. In other words, if the fish is sick what would you do? Treat the fish or change the water? Or if an organ or gland is cancerous what would you do treat the organ or gland or change the water? (44-46) Unfortunately, most groups like Cancer Centers of America, Huntsman Cancer Institute and MD Andersen Cancer Center that advertise integrative, alternative, or naturopathic medicine for reversing a cancerous condition lack proper testing, a targeted method of administration or proper combination with personalized alkalizing treatments. In my 30 
plus years of clinical research experience, providing non-invasive medical diagnostics each week, while providing oral, rectal and IV infusions of alkaline nutrition is the difference that lengthens the quality and quantity of life on over 90 percent of all patients [44-46].

\section{Nutritional Deficiencies and their Negative Health Effects}

Below are some common alkalizing nutrients, their purpose and symptoms, as well as how frequent these deficiencies are seen in the general public in pre-cancerous and cancerous conditions and those patients receiving chemotherapy and/or ionizing radiation.

\section{Sodium (extremely common in 9 out of 10 patients)}

Purpose: Maintains alkalinity of the blood, interstitial and intracellular fluids, and provides the matrix for the transport of electrons for the energy of body cells [52].

Common Sources: Sea salt, celery, green fruit and vegetables, sprouted seeds and grasses.

Symptoms of Deficit: Low sodium bicarbonate levels; acid reflux; excess stomach acid; headache; nausea; compensated, decompensated, and latent tissue acidosis; low energy; low interstitial and intracellular $\mathrm{pH}$; hypertension; heart disease; diabetes; all cancers; and death. [53,54]

\section{Potassium (extremely common)}

Purpose: Increases the alkalizing compound potassium bicarbonate when the body fluids become acidic, maintains alkalinity of the blood, interstitial and intracellular fluids. The major alkalizing element in the body to maintain the alkaline design of all body fluids. The major alkaline buffer in neutralizing metabolic, dietary, respiratory and environmental acids [54-75].

Common Sources: Avocado, almond, green fruit and vegetables, sprouted seeds. nuts and grasses $[54,75]$.

Symptoms of Deficit: Compensated, decompensate and latent tissue acidosis, low energy, low interstitial and intracellular $\mathrm{pH}$, hypertension, heart disease, diabetes, and all cancers.

\section{Calcium (extremely common)}

Purpose: Builds bones, teeth, assists the heart, nerves and muscles.

Common Sources: Green fruit and vegetables, sprouted seeds, nuts and grains, brazil nuts, broccoli, cabbage, dark leafy greens, hazelnuts, and salmon.

Symptoms of Deficit: Osteoporosis, osteomalacia, osteoarthritis, muscle cramps, irritability, acute anxiety and increased colon cancer risk [76].

\section{Magnesium (very common)}

Purpose: More than 300 biochemical reactions, including muscle and nerve function, heart rhythm, immune system, strong bones, regulates calcium, copper, zinc, potassium, vitamin D.
Common Sources: Green fruit and vegetables, sprouted beans, peas, nuts, seeds, whole unprocessed alkalizing grains.

Symptoms of Deficit: Appetite, nausea, vomiting, fatigue cramps, numbness, tingling, seizures, heart spasms, personality changes, heart rhythm and colon cancer.

\section{Zinc (extremely common)}

Purpose: Supports alkalizing, immune system, wound healing, taste and smell, DNA synthesis, normal growth and development during pregnancy, childhood and adolescence.

Common Sources: Found in green fruit and vegetables, sprouted seeds, grains and beans, nuts, whole grains.

Symptoms of Deficit: Growth retardation, hair loss, diarrhea, impotence, eye and skin lesions, loss of appetite, taste, weight loss, mental lethargy [77].

\section{Vitamin E (very common)}

Purpose: This antioxidant regulates oxidation reactions, stabilizes cell membranes, immune function, protects against cardiovascular disease, cataracts and macular degeneration [78].

Common Sources: Found in green fruit and vegetables, sprouted seeds and grains, wheat germ, nuts, seeds, dark leafy greens, avocados, asparagus and certain cold-pressed vegetable oils, like hemp oil [79].

Symptoms of Deficit: Anemia, rupturing of red blood cells, bruising, PMS, hot flashes, eczema, psoriasis, cataracts, wound healing, muscle weakness, sterility.

\section{Vitamin B1 (very common)}

Purpose: Carbohydrate conversion, breaks down fats and protein, assists digestion, the nervous system, skin, hair, eyes, mouth, liver, immune system.

Common Sources: Green fruit and vegetables, sprouted seeds and grains, brown rice, wheat germ, and bran.

Symptoms of Deficit: Age-related cognitive decline, heart problems, Alzheimer's and fatigue.

\section{Vitamin B2 (very common)}

Purpose: Like Vitamin B1, works in carbohydrate conversion, breaks down fats and proteins, assists digestion, the nervous system, skin, hair, eyes, mouth, liver and also metabolism.

Common Sources: Green fruit and vegetables, almonds, sprouted seeds and grains, wheat germ, sprouts of all kinds, including soy sprouts.

Symptoms of Deficit: Anemia, decreased free radical protection, cataracts, poor thyroid function, B6 deficiency, fatigue, and elevated homocysteine [80-84].

\section{Vitamin B3 (less common)}

Purpose: Helps with energy, digestion, nervous system, skin, hair, eyes, liver, eliminates harmful toxins, assists sex and stress hormones and improves circulation. 
Common Sources: Green fruit and vegetables, beets, sprouted seeds, nuts and grains.

Symptoms of Deficit: Cracking, scaling skin, digestive problems, confusion, anxiety, and fatigue [85].

\section{Vitamin B6 (common)}

Purpose: Assists with buffering metabolic acids, protein metabolism, red blood cell (RBC) production, reduces homocysteine, helps nerve and muscle cells, DNA/RNA, B12 absorption, and immune function.

Common Sources: Green fruit and vegetables, especially avocado, sprouted seeds, nuts, and grains.

Symptoms of Deficit: Depression, sleep and skin problems, confusion, anxiety and fatigue [86,87].

\section{Vitamin C (common)}

Purpose: Aids in alkaline buffering activation, second messenger roles (i.e. transmitting hormonal information), blood clotting, cell and cell organelle membrane function, nerve impulse transmission and muscular contraction, tone and irritability. (Not to be confused with High Dose Vitamin C that acts as an oxidative therapy)

Common Sources: Supplements, broccoli, Brussels sprouts, avocado, and all green fruit and vegetables.

Symptoms of Deficit: Muscular and nervous irritability, muscle spasms, muscle cramps and tetany, tooth decay, periodontal disease, depression and possibly hypertension [88-90].

\section{Vitamin D (very common)}

Purpose: Calcium and phosphorus levels, calcium absorption, and bone mineralization.

Common Sources: Sunlight, green fruit and vegetables, sprouted seeds, nuts and beans and fish.

Symptoms of Deficit: Osteoporosis, calcium absorption and thyroid issues, cardiovascular risks and 15 cancer risks [91].

\section{Folate (very common)}

Purpose: Mental health, infant DNA and RNA, adolescence and pregnancy, works with vitamin B12 to regulate RBC production, iron function and reduce homocysteine.

Common Sources: Supplements, sprouted grains, tomato, green vegetables and fruit, avocado, black-eyed peas, sprouted lentils and beans.

Symptoms of Deficit: Anemia, poor immune function, fatigue, insomnia, loss of hair, high homocysteine, colon cancer, and cardiovascular disease [92].

\section{$\mathrm{N}$-aetyl-Cysteine (very common)}

Purpose: Powerful antioxidant or anti-acid, normalizes the alkaline interstitial fluid $\mathrm{pH}$, urinary tract infections, neutralizes metabolic and dietary alcohol poisoning, and protects lungs against toxins from air pollution and tobacco smoke.

Common Sources: Supplements, sprouted grains, sulfurrich vegetables such as garlic, onions, parsley and cruciferous vegetables are particularly helpful in addition to avocados, squash and tomatoes.

Symptoms of Deficit: Anemia, poor immune function, fatigue, insomnia, loss of hair, high homocysteine, urinary tract infections, lung cancer, gastric cancers, colon cancer, ovarian cancer. [92101].

\section{Glutathione (very common)}

Purpose: Potent antioxidant or anti-acid, protects endothelium from dietary and metabolic acids, protects against chemotherapy toxicity, inhibits platelets formation, buffers aflatoxins, infections of the lung, used in cases of Malaria and AIDS, supports immune system, as an alkaline effect on the body fluids.

Common Sources: Supplements, sprouted grains, sulfurrich vegetables such as garlic, onions, parsley and cruciferous vegetables are particularly helpful in addition to avocados, squash and tomatoes.

Symptoms of Deficit: Anemia, poor immune function, fatigue, insomnia, loss of hair, infections, high homocysteine, lung congestion and cancer, gastric cancer, colon cancer, reproductive cancers in men and women, neurological and cardiovascular disease [102-105].

Consider that, if these shortages are found in a healthy population, it is not surprising that patients with a cancerous condition are far worse, due to their high acidity and metabolic demands. Though an alkaline lifestyle and diet is important, it is the amount and quality of care received at therapeutic intravenous, oral, rectal, and respiratory levels that is vital for buffering dietary, metabolic, respiratory and environmental acids in order to maintain the alkaline design of the body fluids in the prevention and treatment of any cancerous condition.

\section{Alkalizing Non-Invasive Rectal Nutrient Infusions}

One important point concerning the infusion of alkalizing nutrients: For those who do not want an invasive, intravenous infusion of alkaline minerals, salts, vitamins, chlorophyll, antioxidants such as glutathione, and-or long-chain polyunsaturated oils, you can elect a non-invasive option: rectal infusion or nebulization (these methods can just as effective). When these supportive nutrients are infused via the anus into the rectum, the hemorrdoidal vein absorbs these alkalizing nutrients into the blood stream for immediate alkalizing benefit [44]. The blood has a very narrow $\mathrm{pH}$ range so these highly alkalizing nutrients are pushed-out into the interstitial fluids to the body cells. This becomes a very important therapy in reducing the metabolic acids that surround the cell and cause the fermentation and break-down of cell-leading to a cancerous condition. 


\section{How Supplementation Can Kick-Start Your Recovery from a Cancerous Condition}

As you can see, nutritional deficiencies can lead to a serious amount of health issues. These problems can become exponential in a patient with a cancerous condition because of the severe strain placed on the patient, especially when chemotherapy and/ or ionizing radiation is involved.

To make matters worse, absorption of salts, minerals, and vitamins is impaired when the gut is congested with undigested protein from beef, chicken, pork, fish and dairy products. This means eating an standard American diet and swallowing a few minerals and vitamins is not sufficient to support the nutritional needs of the patient. Changing to an alkaline diet of fresh organic fruit, vegetables, sprouts, and grasses is essential for long-term health, but in the wake of a cancerous condition, it is hardly enough.

What need to be done is INI and/or RNI therapies. When nutrients are channeled directly into the bloodstream and then to the interstitial fluids, the results are immediate, targeted, and dramatic. Keep in mind, this methodology is not a treatment in-and-of itself. INI and RNI therapies must be combined with personalized alkalizing therapy, alkalizing diet, exercise, proper rest and proper alkalizing water, then a revolutionary improvement in over-all health can begin [44-46].

Using 3-D Full Body Bio-Electro Scanning (FBBES), Full Body Thermography (FBT), Full Body Ultrasound (FBU), Live Blood Analysis (LBA) and Dried Blood Analysis (DBA) to Determine the Best Possible Strategy for Preventing and/or Reversing Any Cancerous Condition and to Monitor Treatment Progress [106].

In modern day oncology, surgeons biopsy the lymph nodes to determine how cancer is spreading or provide staging [107] Lymphocytes, a type of white blood cell that is found in these lymph nodes which are catch-basins for acidic waste and cancerous cells are responsible for breaking-down and removing cellular acidic waste and cancerous cells. Impaired lymphocytes and lymph nodes are at least one major factor in the many areas I test for (as described below) ohysiologically using (FBT) functionality using (FBBES) (as described below). The lymphatic system, the lymph nodes and the lymphocytes themselves must be functional in preventing and reversing any cancerous condition.

Using electrodes attached to the head, hands, and feet, the functionality of the lymphatic system, circulatory system, muscular system, skeletal system, endocrine system, neurological system, reproductive system, vascular system, digestive system, and respiratory system can be noninvasively analyzed. Interstitial chemistry, interstitial $\mathrm{pH}$ for metabolic acidosis, and the electroconductivity of the cells to determine the state of health of all organs, glands, and tissues in the prevention and reversal of any cancerous condition [108].

This test also accounts for nutritional deficiencies and metabolic alkalosis or acidosis by measuring the interstitial chemistry, interstitial $\mathrm{pH}$, and the electro-conductivity if the cells of the body. Measuring the $\mathrm{pH}$ of the interstitial fluids is more revealing as it pertains to the $\mathrm{pH}$ and chemistry than measuring the blood fluids of a cancerous condition since the blood is always trying to maintain its delicate alkaline $\mathrm{pH}$ of 7.365 and will not vary much. Based upon my theory that cancer is a compromised acidic environment of the interstitial fluids which may negatively affect the state of health of all body cells which make up the organs, glands and tissues [71,72]. It is significantly more important to measure interstitial and intracellular fluids than blood fluids in order to obtain a correct chemistry and $\mathrm{pH}$ when making nutritional recommendations in the prevention and treatment of a cancerous condition $[44-46,106,108,109]$.

The following are quantitative measurements in healthy patients, without cancer, comparing blood fluids with intracellular and interstitial fluids of the body compartments as a benchmark to determine deficiencies in alkalizing minerals, protein, and whether or not the patient is in metabolic acidosis, a precancerous, or cancerous condition (Note: all cancer patients are in interstitial metabolic acidosis, low in interstitial sodium and high in interstitial calcium and potassium): [108,109]

1) Sodium: $\mathrm{Na}+\mathrm{mEq} / \mathrm{l}$

Venous blood: 130, Arterial blood: 137, Capillary blood: 135, Intracellular fluid: 10 and Interstitial fluid: 135

2) Potassium: $K+m E q / l$

Venous blood: 3.2, Arterial blood: 3.5, Capillary blood: 4, Intracellular fluid: 140 and Interstitial fluid: 3.17

3) Calcium: $\mathrm{Ca}++\mathrm{mEq} / \mathrm{l}$

Venous blood: 2.5, Arterial blood: 2.2, Capillary blood: 2.3, Intracellular fluid: 0.0001 and Interstitial fluid: 1.55

4) Magnesium: Mg mEq/l

Venous blood: 0.64, Arterial blood: 0.62, Capillary blood: 0.60, Intracellular fluid: 58 and Interstitial fluid: 0.50

5) Chloride: $\mathrm{Cl}-\mathrm{mEq} / \mathrm{l}$

Venous blood: 104, Arterial blood: 101, Capillary blood: 103, Intracellular fluid: 4 and Interstitial fluid: 106

6) Bicarbonate: $\mathrm{HCO} 3 \mathrm{mEq} / \mathrm{l}$

Venous blood: 22, Arterial blood: 24, Capillary blood: 23, Intracellular fluid: 10 and Interstitial fluid: 24

7) Phosphorus: P mE/l

Venous blood: 2.5, Arterial blood: 2.3, Capillary blood: 2, Intracellular fluid: 75 and Interstitial fluid: 0.70

8) Sulfate: SO4 mEq/l

Venous blood: 0.8, Arterial blood: 0.6, Capillary blood: 0.5, Intracellular fluid: 2 and Interstitial fluid: 0

9) Glycemia mg/dl

Venous blood: 1, Arterial blood: 1, Capillary blood: 1.01, Intracellular fluid: 0.20 and Interstitial fluid: 0.90 
10) Cholesterol mg/dl

Venous blood: 0.66, Arterial blood: 0.630, Capillary blood: 0.676, Intracellular fluid: 0.2 and Interstitial fluid: 0.188

11) Partial Pressure of Oxygen or PO2 mmHg

Venous blood: 80, Arterial blood: 90, Capillary blood: 89, Intracellular fluid: 20 and Interstitial fluid: 87.2

12) Carbon Dioxide Or PCO2

Venous blood: 46, Arterial blood: 40, Capillary blood: 42 , Intracellular fluid: 50 and Interstitial fluid: 46

13) $\mathrm{pH}$ or potential of hydrogen

Venous blood: 7.36, Arterial blood: 7.4, Capillary blood: 7.38, Intracellular fluid: 7.2 and Interstitial fluid: 7.36

14) Protein g/dl

Venous blood: 72, Arterial blood: 74, Capillary blood: 73.7, Intracellular fluid: 68 and interstitial fluid: 20.6

As deficiencies are corrected in the intracellular and interstitial fluids with key alkalizing nutritional treatments, patients see the difference in the improved interstitial $\mathrm{pH}$ and chemistry counts through follow-up tests using quantitative non-invasive 3-D FBBES. They also feel the difference physiologically and functionally with increased energy and vitality [106,108,109]

This is how I know proper alkalizing nutritional support in any cancerous condition is important in the prevention and treatment of cancer, the metastasis of cancer, and the shrinking of a cancerous cyst or mass without chemotherapy and-or radiation. The best part about these alkalizing nutritional treatments is they are helpful in most, if not in all cancerous conditions [44-46].

The following case study is with one of my patients who were diagnosed by biopsy with inflammatory ductal cell carcinoma who reversed her cancerous condition without chemotherapy, radiotherapy, and surgery [106].

By using breast thermography and ultrasound also referred to as sonography for tumor location and size you can see the week by week thermography progress of a $14.2 \mathrm{~cm}$ tumor in the left breast reduce to less than $2 \mathrm{~cm}$ in 7 weeks of treatment using ANI protocol (as outlined in this article and in Chapter 11, pH Miracle revised and updated) [44-46,106].

The safest, painless, non-invasive, affordable full body screening tests are a combination of a Medical Diagnostic Ultrasound and Thermography, which may give the Physician about $95 \%$ accuracy in detecting breast cancer [106].

Full Body Thermography (FBT) is a physiological, non-invasive screening procedure that detects and records infrared heat emissions from the pre-cancerous or cancerous area, which can aid in the early detection of abnormal changes in body tissues, organ, and glands [110]. FBT offers information that no other procedure can provide. The procedure is based on the principle that chemical and blood vessel activity in both pre-cancerous or cancerous tissue, and the area surrounding a developing cancer, is almost always higher in temperature than in the normal tissue.

Since pre-cancerous and cancerous masses are highly metabolic tissues, they need an abundant supply of nutrients to maintain their growth. The cells release substances that stimulate the formation of new blood vessels (neoangiogenesis). This process results in an increase in surface temperatures of the affected tissue, organ, or gland [110].

The most promising aspect of medical diagnostic FBT is its ability to spot abnormalities years before the tumor is seen on any other anatomical test. Since thermal imaging detects changes at the cellular level, this test can detect activity 8 to 10 years before any other test [106,110-112]. This makes it unique in that it affords the physician the opportunity to view changes before the actual formation of the cancerous tumor.

Studies have shown that by the time a tumor has grown sufficiently to be detectable by physical examination or mammography; it has been growing for about seven yearsachieving more than 25 doublings of the malignant cell colony $[106,110-113]$. At 90 days there are two cells, at one year there are 16 cells, and at five years there are 1,048,576 cells-an amount that is still undetectable by a mammogram. Thermography has the ability to provide the patient with future risk assessment. If discovered, certain thermographic risk markers can warn the patient that she or he needs to work closely with their physician with regular checkups to monitor health [106].

Full-body Ultrasound (FBU) is an anatomical, non-invasive, and painless screening test without ionized radiation. FBU uses sound waves to outline a part of the body. For this test, a small instrument called a transducer is placed on the skin (which is often first lubricated with ultrasound gel) and emits sound waves off body tissues. The echoes are converted by a computer into an image that is displayed on a computer screen.

FBU imaging is "real-time," meaning that it can show exactly what is happening in the tissue, organ, or gland at that moment: helping to distinguish between cysts (fluid-filled sacs) and solid masses; detect increased vascularity around or within the mass; and to see the shape, exact size, and location of the mass, cyst, calcification, or dilated mammary ducts.

These safe medical diagnostic tests can be done on early basis as a regular check up-or more often if a problem was detected with the FBBES and FBT to monitor the efficacy of the noninvasive alkalizing nutritional treatment progress.

\section{Non-Invasive Hematological Blood Tests}

A live (LBA) and dried blood analysis (DBA) is used for detection and monitoring of dietary and metabolic dysfunction in the prevention of ALL sickness and disease, including cancer [114].

The live blood phase contrast microscopy assessment and the dried blood brightfield mycotoxic oxidative stress assessment are two unique blood tests that are used as pre- screening tests combined with Diagnostic Medical Ultrasound (FBU), Thermography (FBT) and Bio- electro Scan (FBBES) to monitor 
dietary and metabolic dysfunction-thereby taking the guesswork out of diet determination and the selection of an appropriate natural hygiene health and fitness protocol [115-116].

\section{What are the Benefits?}

There are many benefits to having your live and dried blood analyzed. You can see how generally healthy you are, $\mathrm{PH}$ imbalances, indications of levels of toxicity, nutrient deficiency, free radical stress, the quality of your diet, how well any supplements may be working for you and how well your systems are working to detoxify your body [115].

Most importantly, for many people they can see for themselves the dynamic activity going on inside their body for the first time. Many people begin to understand the impact of their diet and lifestyle on their body and begin to grasp the need to commit to taking care of their health.

\section{How Does it Work?}

Live blood analysis allows you to view the red and white blood cells in the blood, the platelets and the blood plasma. Imbalances seen in the blood will affect organs and tissues leading to malfunction and eventually illness. If our red blood cells are not perfectly shaped, with a proper structure, flexibility and fluidity their ability to travel around the body and do their job is severely compromised. This leads to tissue levels of oxygen and nutrients falling, which translates to low energy, fatigue and a general sense of feeling unwell as well as more serious problems. Similarly, dried blood analysis can show levels of oxidative stress and toxicity in the body $[115,116]$.

Based upon the observations I then recommend specific protocols to cleanse and rejuvenate your blood. This may include herbs, natural supplements and detoxification protocols as well as simple lifestyle and dietary suggestions [44-46].

Case Study 2: Patient Medical Diagnosed with Prostate Cancer with 3 Lesions, Hepatitis C and Cytomegalovirus (CMV)
1) Prostate cancer - 3 lesions
2) Hepatitis C
3) CMV
4) Arteriosclerotic plaque
5) High Bilirubin
6) High C-reactive protein
7) High cholesterol
8) High PSA
9) High Gleason score
10) Low testosterone

\section{Duration of Treatment: April 2012 to November 2014}

The following are a few of the first pictures of LBA and DBA blood micrographs taken from the patient in April of 2012. The patterns of the LBA and DBA blood tests were consistent with prostate cancer showing several polymerized protein pools (PPP) in the center of the coagulated blood [115].

After 6 months of following the alkaline diet and lifestyle with Alkaline Nutritional Therapy (ANT) and RNT his LBA blood showed incredible improvement with normal healthy blood. The DBA blood showed a reduction in polymerized protein pools (PPP) in the center of the coagulated blood indicating improvement in the health of the prostate.

On November 2014 his live and dried blood shows no indications of malignancy. Live and dried blood showing the normal healthy profiles (Figure 1). [Figure 1: Treatment Progress of a Patient with Prostate Cancer, Hepatitis $\mathrm{C}$ and Cytomegalovirus (CMV) Using Non-Invasive Live and Dried Blood Cell Analysis. The live and dried blood cell pictures begin with April of 2012 showing irregular patterns in the red blood cells and white polymerized protein pools in the center of the dried blood consistent with inflammation and/or malignancy of the reproductive organs. The live and dried blood pictures center on September 2012 shows improvement with normal healthy red blood cells and smaller polymerized protein pools in the center of the dried blood test. A final live and dried blood cell analysis was done on November 2014 showing normal health red blood cells and a normal health dried blood cell coagulation indicating a potential reversal of the diagnosed condition].

\section{Results}

October 2014 biopsy, MRI and blood tests showed that all conditions of prostate cancer with 3 lesions, Hepatitis C and Cytomegalovirus (CMV) were reversed.

Also, the current conventional blood report of November 2014, showed normal cholesterol, sclerotic plaque gone, normal bilirubin, normal C-reactive protein, normal PSA and normal Testosterone levels.

\section{Conclusion}

Early detection is critical for any cancerous condition, which includes self examination and safe, painless, non-invasive medical diagnostic. The early detection scans include a Full Body Bioelectro Scan (FBBES), Full Body Thermography (FBT), a Full Body Ultrasound (FBU) scan and a Live Blood Analysis(LBA) with a Dried Blood Analysis (DBA). All diagnostic scans are free from ionizing radiation and are coupled with a supportive alkalizing nutritional diet, Intravenous Nutritional Infusion (INI) and Rectal Nutritional Infusion (RNI) even if the patient is receiving chemotherapy and/or radiation.

I have found clinically that this non-invasive approach for any precancerous or cancerous condition will save lives and improve the quality and quantity of life of the patient. Reversing an existing cancerous condition and preventing the risk of metastasis has been demonstrated in over 90 percent of all cases. using this alkalizing lifestyle, diet, alkalizing Intravenous Nutritional Infusion (INI) and Rectal Nutritional Infusion (RNI) treatment therapy [44-46,106,117,118-132]. 


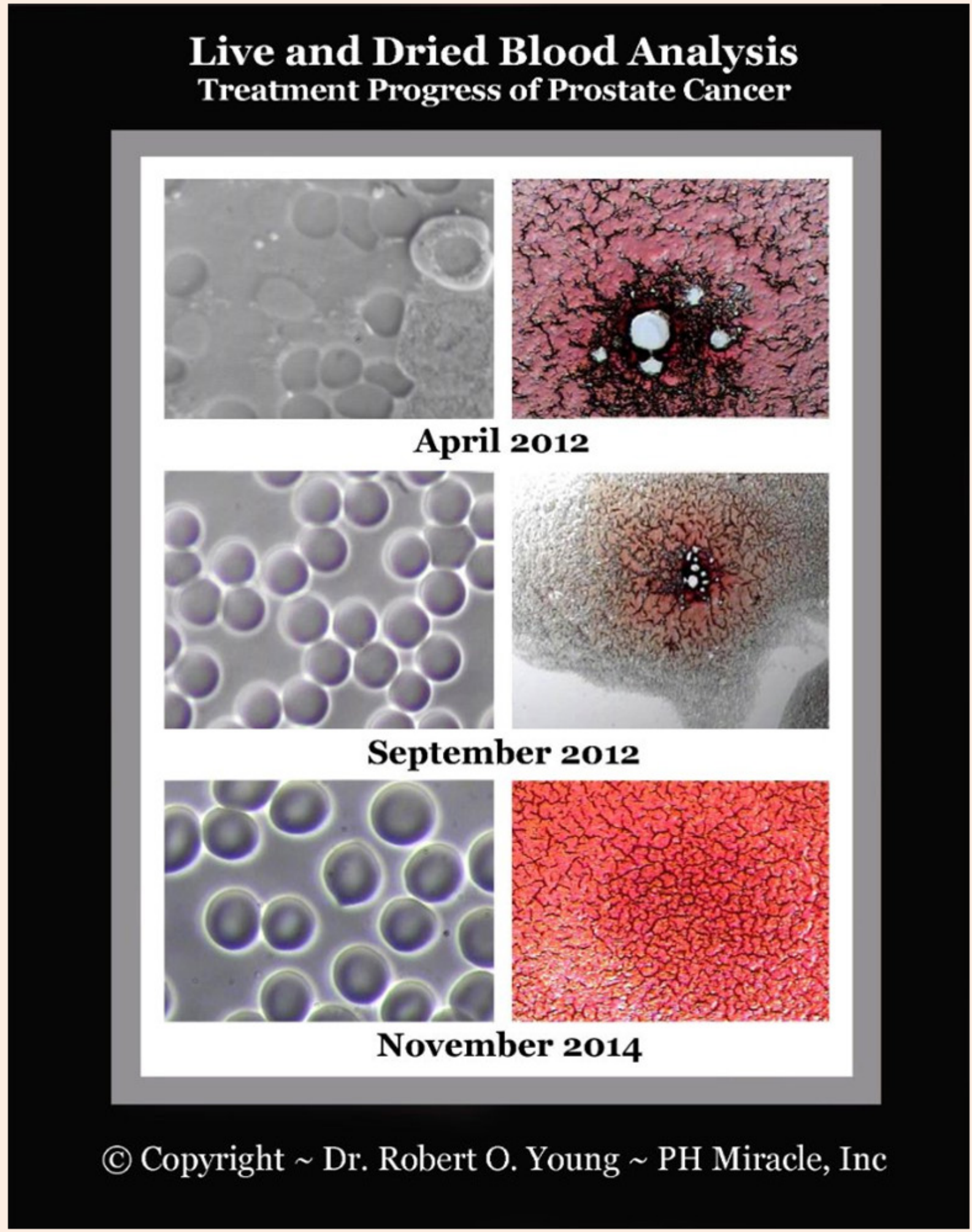

Figure 1: Treatment Progress of a Patient with Prostate Cancer, Hepatitis C and Cytomegalovirus (CMV) Using Non-Invasive Live and Dried Blood Cell Analysis. 


\section{References}

1. Adams KM, Lindel KC, Kohlmiier M, Zeisel SH (2006) Status of nutrition education in medical schools. Am J Clin Nutr 83(4): 941S-944S

2. Bruer RA, Schmidt RE, Chapel T (1993) Nutrition education for physicians: alternative federal roles for creating an improved system. Macro International, Washington, USA.

3. Davis CH (1994) The report to Congress on the appropriate federal role in assuring access by medical students, residents, and practicing physicians to adequate training in nutrition. Public Health Rep 109(6): 824-826.

4. National Academy of Sciences (1985). Nutrition education in US medical schools. National Academy Press, Washington, DC, USA.

5. Feldman EB (1991) Educating physicians in nutrition-a view of the past, the present, and the future. Am J Clin Nutr 54(4): 618-622.

6. Darer JD, Hwang W, Pham HH, Bass EB, Anderson G (2004) More training needed in chronic care: a survey of US physicians. Acad Med 79(6): 541-548.

7. All schools reports (2004). Association of American Medical Colleges Medical School Graduation Questionnaire.

8. Torti F, Adams K, Edwards L, Lindell K, Zeisel S (2001) Survey of nutrition education in U.S. medical schools-an instructor based analysis. Med Educ Online 6: 8.

9. Association of American Medical Colleges Curriculum directory.

10. Weinsier RL, Boker JR, Brooks CM, Kushner RF, Visek WJ, et al. (1989) Priorities for nutrition content in a medical school curriculum: a national consensus of medical educators. Am J Clin Nutr 50(4): 707-712.

11. Mihalynuk TV, Scott CS, Coombs JB (2003) Self-reported nutrition proficiency is positively correlated with the perceived quality of nutrition training of family physicians in Washington State. Am J Clin Nutr 77(5): 1330-1336.

12. Kushner RF (1995) Barriers to providing nutrition counseling by physicians: a survey of primary care practitioners. Prev Med 24(6): 546-552.

13. Mihalynuk TV, Knopp RH, Scott CS, Coombs JB (2004) Physician informational needs in providing nutritional guidance to patients. Fam Med 36(10): 722-726.

14. Groos E, Walker L, Masters JR (1986) Intravesical chemotherapy Studies on the relationship between $\mathrm{pH}$ and cytotoxicity. Cancer 58(6): 1199-1203.

15. Smith SR, Martin PA, Edwards RH (1991) Tumour pH and response to chemotherapy: an in vivo 31P magnetic resonance spectroscopy study in non-Hodgkin's lymphoma. Br J Radiol 64(766): 923-928.

16. Raghunand N, Gillies RJ (2001) pH and chemotherapy. Novartis Found Symp 240: 199-211.

17. Raghunand N, He X, Van Sluis R, Mahoney B, Baggett B, et al. (1999) Enhancement of chemotherapy by manipulation of tumour $\mathrm{pH}$. Br J Cancer 80(7): 1005-1011.

18. Sergei I, Grivennikov, Florian R, Greten, Michael K (2010) Immunity, Inflammation, and Cancer. Cell 140(6): 883-899

19. Joydeb KK, Young-Joon S (2008) Inflammation: Gearing the journey to cancer. Mutation Research 659: 15-30.
20. Researchers examine how BRD4 contributes to sustained presence of NF-kappa B in cancer cells.

21. Carmen B, Maria JP, Maria UL, Josefa C, Saioa G, et al. (2009) The Epidermal Growth Factor Receptor: A Link Between Inflammation and Liver Cancer. Exp Biol Med 234(7): 713-725.

22. Simone CB, Simone NL Simone V (2007) Antioxidants and other Nutrients Do Not Interfere With Chemotherapy or Radiation Therapy and Increase Kill and Survival. Altern Ther Health Med 13(2): 40-47.

23. Nick Barker, Johan H van Es, Jeroen Kuipers, Pekka Kujala, Maaike van den Born, et al. (2007) Identification of stem cells in small intestine and colon by marker gene Lgr5. Nature 449, 1003-1007 doi: $10.1038 /$ nature06196.

24. Waugh A, Grant A (2007) Anatomy and Physiology in Health and Illness. $10^{\text {th }}(\mathrm{edn})$, Churchill Livingstone, Philadelphia, Pa, USA.

25. Oceans reveal further impacts of climate change (2010) ScienceDaily, University of Alabama at Birmingham.

26. Hoegh-Guldberg O, Mumby PJ, Hooten AJ, Steneck RS, Greenfield $P$, et al. (2007) Coral reefs under rapid climate change and ocean acidification. Science 318(5857): 1737-1742.

27. Dam-ampai SO, Onthong J, Nilnond C (2005) Effect of cattle manure and dolomite on soil properties and plant growth in acid upland soils. Songklanakarin Journal of Science and Technologh 27(supplement 3): 727-737.

28. Ströhle A, Hahn A, Sebastian A (2010) Estimation of the dietdependent net acid load in 229 worldwide historically studied hunter-gatherer societies. Am J Clin Nutr 91(2): 406-412.

29. Sebastian A, Frassetto LA, Sellmeyer DE, Merriam RL, Morris RC Jr (2002) Estimation of the net acid load of the diet of ancestral preagricultural Homo sapiens and their hominid ancestors. Am J Clin Nutr 76(6): 1308-1316.

30. Frassetto L, Morris RC Jr, Sellmeyer DE, Todd K, Sebastian A (2001) Diet, evolution and aging-the pathophysiologic effects of the postagricultural inversion of the potassium-to-sodium and base-tochloride ratios in the human diet. European Journal of Nutrition 40(5): 200-213.

31. Konner M, Eaton SB (2010) Paleolithic nutrition: twenty-five years later. Nutr Clin Pract 25(6): 594-602.

32. Lindeman RD, Goldman R (1986) Anatomic and physiologic age changes in the kidney. Experimental Gerontology. 21(4-5): 379406.

33. Reddy ST, Wang CY, Sakhaee K, Brinkley L, Pak CY (2002) Effect of low-carbohydrate high-protein diets on acid-base balance, stoneforming propensity, and calcium metabolism. Am I Kidney Dis $40(2): 265-274$

34. Groos E, Walker L, Masters JR (1986) Intravesical chemotherapy Studies on the relationship between $\mathrm{pH}$ and cytotoxicity. Cancer 58(6): 1199-1203.

35. Smith SR, Martin PA, Edwards RHT (1991) Tumour $\mathrm{pH}$ and response to chemotherapy: an in vivo $31 \mathrm{P}$ magnetic resonance spectroscopy study in non-Hodgkin's lymphoma. Br J Radiol 64(766): 923-928.

36. Raghunand N, Gillies RJ (2001) pH and chemotherapy. Novartis Found Symp 240: 199-211.

37. Raghunand N, He X, Van Sluis R, Mahoney B, Baggett B, et al. (1999) 
Enhancement of chemotherapy by manipulation of tumour $\mathrm{pH} . \mathrm{Br}]$ Cancer 80(7): 1005-1011.

38. Louis Pasteur (1879) Studies on fermentation: The diseases of beer, their causes, and the means of preventing them. Macmillan Publishers, UK.

39. http://www.biodiversitylibrary.org/bibliography/32905\#/ summary

40. Warburg O (1956) On the Origin of Cancer Cells. Science 123(3191) 309-314.

41. Wittig R, Coy JF (2008) The Role of Glucose Metabolism and Glucose-Associated Signaling in Cancer. Perspect Medicin Chem 1: 64-82.

42. Keith BA (1978) The Mechanism Involved and a High pH Therapy Cancer Brewer Foundation, USA.

43. Kourtidis A, Ngok SP, Pulimeno P, Feathers RW, Carpio LR, et al. (2015) Distinct E-cadherin-based complexes regulate cell behaviour through miRNA processing or Src and p120 catenin activity. Nat Cell Biol 17(9): 1145-1157.

44. Nishikawa-Ogawa M, Wanibuchi H, Morimura K, Anna Kinoshita Takayuki Nishikawa, et al. (2006) N-acetyl cysteine and S-methylcysteine inhibit MeIQx rat hepatocarcinogenesis in the post-initiation stage. Carcinogenesis. 27(5): 982-988.

45. Van Schooten FJ, Besaratinia A, De Flora S, D'Agostini F, Izzotti A, et al. (2002) Effects of oral administration of N-acetyl-L-cysteine: a multi-biomarker study in smokers. Cancer Epidemiol Biomarkers Prev 11(2):167-175.

46. Ponz de Leon M, Roncucci L (1997) Chemoprevention of colorecta tumors: role of lactulose and of other agents. Scand J Gastroenterol Suppl 222: 72-75

47. Estensen RD, Levy M, Klopp SJ, Galbraith AR, Mandel JS, et al (1999) N-acetyl cysteine suppression of the proliferative index in the colon of patients with previous adenomatous colonic polyps. Cancer Lett 147(1-2): 109-114.

48. Roxanne Nelson (2013) One Size Fits All Drug Dosing Give Suboptimal Results. Medscape.

49. Prigerson HG, Bao Y, Shah MA, Paulk ME, LeBlanc TW (2015) Chemotherapy Use, Performance Status, and Quality of Life at the End of Life. JAMA Oncol 1(6): 778-784.

50. Cancer Treatment \& Survivorship, Facts \& Figures, Estimated Numbers of Cancer Survivors by State as of January 1, 2014

51. Odes HS, Hogan DL, Steinbach JH, Ballesteros MA, Koss MA (1992) Measurement of gastric bicarbonate secretion in the human stomach: different methods produce discordant results. Scand J Gastroenterol 27(10): 829-836.

52. AF Basile, Ahyl AC, Feldman LC, Williams JR, Mooney PM (2014) Effects of sodium ions on trapping and transport of electrons at the SiO/4H-SiC interface. J of Appl Phys 115, 034502.

53. Campling BG, Sarda IR, Baer KA, Pang SC, Baker HM, et al. (1995) Secretion of atrial natriuretic peptide and vasopressin by small cell lung cancer. Cancer 75(10): 2442-2451.

54. US Department of Agriculture: Report of the Dietary Guidelines Advisory Committee Report on the Dietary Guidelines for Americans, 2010: Sodium, Potassium, and Water

55. Aronson PS, Giebisch G (2011) Effects of pH on potassium: new explanations for old observations. J Am Soc Nephrol 22: 1981.
56. Sterns RH, Cox M, Feig PU, Singer I (1981) Internal potassium balance and the control of the plasma potassium concentration. Medicine (Baltimore) 60: 339

57. Adrogué HJ, Madias NE (1981) Changes in plasma potassium concentration during acute acid-base disturbances. Am J Med 71: 456.

58. Adrogué $\mathrm{HJ}$, Madias NE (2004) PCO2 and [K+]p in metabolic acidosis: certainty for the first and uncertainty for the other. J Am Soc Nephrol 15: 1667.

59. Magner PO, Robinson L, Halperin RM (1988) The plasma potassium concentration in metabolic acidosis: a re-evaluation. Am J Kidney Dis 11: 220.

60. Wiederseiner JM, Muser J, Lutz T (2004) Acute metabolic acidosis characterization and diagnosis of the disorder and the plasma potassium response. J Am Soc Nephrol 15: 1589.

61. Fulop M (1979) Serum potassium in lactic acidosis and ketoacidosis. N Engl J Med 300: 1087.

62. Graber M (1993) A model of the hyperkalemia produced by metabolic acidosis. Am J Kidney Dis 22: 436.

63. Adrogué HJ, Chap Z, Ishida T, Field JB (1985) Role of the endocrine pancreas in the kalemic response to acute metabolic acidosis in conscious dogs. J Clin Invest 75: 798

64. Szylman P, Better OS, Chaimowitz C, Rosler A (1976) Role of hyperkalemia in the metabolic acidosis of isolated hypoaldosteronism. N Engl J Med 294: 361

65. Altenberg GA, Aristimuño PC, Amorena CE, Taquini AC (1989) Amiloride prevents the metabolic acidosis of a $\mathrm{KCl}$ load in nephrectomized rats. Clin Sci (Lond) 76: 649.

66. Rose BD (2001) Post TW. Clinical Physiology of Acid-Base and Electrolyte Disorders, ( $5^{\text {th }}$ edn), McGraw-Hill, New York. p. 347

67. DuBose TD Jr, Good DW (1991) Effects of chronic hyperkalemia on renal production and proximal tubule transport of ammonium in rats. Am J Physiol 260: F680.

68. DuBose TD Jr, Good DW (1992) Chronic hyperkalemia impairs ammonium transport and accumulation in the inner medulla of the rat. J Clin Invest 90: 1443

69. Good DW (1994) Ammonium transport by the thick ascending limb of Henle’s loop. Annu Rev Physiol 56:623.

70. Attmane-Elakeb A, Mount DB, Sibella V (1998) Stimulation by in vivo and in vitro metabolic acidosis of expression of rBSC-1, the $\mathrm{Na}+\mathrm{K}+(\mathrm{NH} 4+)-2 \mathrm{Cl}-$ cotransporter of the rat medullary thick ascending limb. J Biol Chem 273: 33681.

71. Bourgeois S, Meer LV, Wootla B (2010) NHE4 is critical for the renal handling of ammonia in rodents. J Clin Invest 120:1895.

72. Sabatini S, Kurtzman NA (1984) The maintenance of metabolic alkalosis: factors which decrease bicarbonate excretion. Kidney Int 25: 357.

73. COOKE RE, SEGAR WE, CHEEK DB (1952) The extrarenal correction of alkalosis associated with potassium deficiency. J Clin Invest 31: 798.

74. Carlisle EJ, Donnelly SM, Vasuvattakul S (1991) Glue-sniffing and distal renal tubular acidosis: sticking to the facts. J Am Soc Nephrol 1: 1019

75. Marla Heller (2007) The DASH Diet Action Plan, Amidon Press. 
76. Rethinking Cancer.

77. Calcium supplementation may attenuate the hyperproliferation and hyperplasia induced in the mouse colon by a Western-style diet.

78. Richter F, Newmark HL, Richter A, Leung D, Lipkin M (1995) Inhibition of Western-diet induced hyperproliferation and hyperplasia in mouse colon by two sources of calcium. Carcinogenesis 16(11): 2685-2689.

79. Substances : Calcium : CK(232) : AC(35)Diseases : Colon Cancer : CK(895) : AC(233), Western-Style Diet Induced Toxicity : CK(6) : AC(3)Pharmacological Actions : Antiproliferative : CK(1061) : $\mathrm{AC}(775)$

80. Wark PA, Lau R, Norat T, Kampman E (2012) "Magnesium intake and colorectal tumor risk: a case-control study and meta-analysis. Am J Clin Nutr 96(3): 622-631.

81. Costello LC, Feng P, Milon B, Tan M, Franklin RB (2004) Role of zinc in the pathogenesis and treatment of prostate cancer: critical issues to resolve. Prostate Cancer and Prostatic Dis 7(2): 111-117.

82. Bjelakovic G, Nikolova D, Gluud LL, Simonetti RG, Gluud C (2012) Antioxidant supplements for prevention of mortality in healthy participants and patients with various diseases. Cochrane Database Syst Rev 3: CD007176.

83. Chalasani N, Younossi Z, Lavine JE, Diehl AM, Brunt EM, et al. (2012) The diagnosis and management of non-alcoholic fatty liver disease: Practice guideline by the American Association for the Study of Liver Diseases, American College of Gastroenterology, and the American Gastroenterological Association. Am J Gastroenterol 55(6): 2005-2023.

84. Caraballoso M, Sacristan M, Serra C, Bonfill X (2003) Drugs for preventing lung cancer in healthy people. Cochrane Database Syst Rev (2): CD002141.

85. Hanberry BS, Berger R, Zastre JA (2014) High-dose vitamin B1 reduces proliferation in cancer cell lines analogous to dichloroacetate. Cancer Chemother Pharmacol 73(3): 585-594.

86. Bareford LM, Avaritt BR, Ghandehari H, Nan A, Swaan PW (2013) Riboflavin-targeted polymer conjugates for breast tumor delivery. Pharm Res 30(7): 1799-1812.

87. Ainiwaer J, Tuerhong A, Hasim A, Chengsong D, Liwei Z, et al. (2013) Association of the plasma riboflavin levels and riboflavin transporter (C20orf54) gene statuses in Kazak esophageal squamous cell carcinoma patients. Mol Biol Rep 40(5): 3769-3775.

88. Bassett J K, Severi G, Hodge A M, Baglietto L, Hopper JL, et al. (2013) Dietary intake of B vitamins and methionine and colorectal cancer risk. Nutr Cancer 65(5): 659-667.

89. Powers HJ (2003) Riboflavin (vitamin B-2) and health. Am J Clin Nutr 77(6): 1352-1360.

90. Chaves Neto AH, Pelizzaro-Rocha KJ, Fernandes MN, FerreiraHalder CV (2014) Antitumor activity of irradiated riboflavin on human renal carcinoma cell line 786-0. Tumour Biol 36(2): 595604

91. Powers HJ (2005) Interaction among folate riboflavin genotype and cancer with reference to colorectal and cervical cancer. J Nutr 135(12 suppl): 2960S-2966S

92. Kirkland JB (2003) Niacin and carcinogenesis. 46(2): 110-118.
93. Zhang SM, Moore SC, Lin J, Cook NR, Manson JE, et al. (2006) Folate vitamin B6 multivitamin supplements and colorectal cancer risk in women. Am J Epidemiol 163(2): 108-115.

94. Ma E, Iwasaki M, Kobayashi M, Kasuga Y, Yokoyama S, et al. (2009) Dietary intake of folate vitamin B2 vitamin B6 vitamin B12 genetic polymorphism of related enzymes and risk of breast cancer: a casecontrol study in Japan. Nutr Cancer 61(4): 447-456.

95. Kirkland JB (2003) Niacin and carcinogenesis. 46(2): 110-118.

96. Cameron E, Pauling L (1976) Supplemental ascorbate in the supportive treatment of cancer: Prolongation of survival times in terminal human cancer. Proc Natl Acad Sci U S A 73(10): 36853689.

97. Cabanillas F (2010) Vitamin C and cancer: what can we conclude--1,609 patients and 33 years later?. Puerto Rico health sciences journal 29 (3): 215-217.

98. Grant WB (2012) Ecological studies of the UVB-vitamin D-cancer hypothesis. Anticancer Res 32(1): 223-236. , Substances : Vitamin D : CK(1682) : AC(238)Diseases : Bladder Cancer : CK(186) : AC(60), Breast Cancer : CK(2372) : AC(660), Cervical Cancer : CK(378) : AC(69), Colon Cancer : CK(895) : AC(233), Colorectal Cancer : CK(877) : AC(321),Endometrial Cancer : CK(269) : AC(45), Esophageal Cancer : CK(328) : AC(55), Hodgkin Lymphoma : CK(53) : AC(7), Lung Cancer : CK(496) : AC(198), NonHodgkin Lymphoma : CK(525) : AC(67),Ovarian Cancer : CK(154) : AC(58), Pancreatic Cancer : CK(530) : AC(168), Renal Cancer : CK(25) : AC(4), Vulvar Cancer : CK(52) : AC(4), Therapeutic Actions : Sunlight exposure : CK(432) : AC(39), Pharmacological Actions : Chemopreventive : $\mathrm{CK}(1528)$ : AC(382)

99. Jaszewski R, Misra S, Tobi M, Ullah N, Naumoff JA, et al. (2008) Folic acid supplementation inhibits recurrence of colorectal adenomas: a randomized chemoprevention trial. World J Gastroenterol 14(28): 4492-4498.

100. Guan D, Xu Y, Yang M, Wang H, Wang X, et al. (2010) N-acetyl cysteine and penicillamine induce apoptosis via the ER stress response-signaling pathway. Mol Carcinog 49(1): 68-74.

101. Li J, Tu HJ, Li J, Dai G, Dai YC, et al. (2007) N-acetyl cysteine inhibits human signet ring cell gastric cancer cell line (SJ-89) cell growth by inducing apoptosis and DNA synthesis arrest. Eur J Gastroenterol Hepatol 19(9): 769-774.

102. Yang J, Su Y, Richmond A (2007) Antioxidants tiron and N-acetylL-cysteine differentially mediate apoptosis in melanoma cells via a reactive oxygen species-independent NF-kappaB pathway. Free Radic Biol Med 42(9): 1369-1380.

103. Krasnowska EK, Pittaluga E, Brunati AM, Brunelli R, Costa G, et al. (2008) N-acetyl-l-cysteine fosters inactivation and transfer to endolysosomes of c-Src. Free Radic Biol Med 45(11): 1566-1572.

104. Reliene R, Pollard JM, Sobol Z, Trouiller B, Gatti RA, et al. (2009) $\mathrm{N}$-acetyl cysteine protects against ionizing radiation-induced DNA damage but not against cell killing in yeast and mammals. Mutat Res 665(1-2): 37-43.

105. Cascinu S, Cordella L, Del Ferro E, Fronzoni M, Catalano G, et al (1995) Neuroprotective effect of reduced glutathione on cisplatinbased chemotherapy in advanced gastric cancer: a randomized double-blind placebo-controlled trial. J Clin Oncol 13(1): 26-32.

106. Hercbergs A, Brok-Simoni F, Holtzman F, Bar-Am J, HJ Brenner, et al. (1992) Erythrocyte glutathione and tumor response to chemotherapy. Lancet 339(8801): 1074-1076. 
107. Schmidinger M, Budinsky AC, Wenzel C, Piribauer M, Brix R, et al. (2000) Glutathione in the prevention of cisplatin induced toxicities. A prospectively randomized pilot trial in patients with head and neck cancer and non small cell lung cancer. Wien Klin Wochenschr 112(14): 617-623.

108. Wien Klin Wochenschr pilot trial in patients with head and neck cancer and non small cell lung cancer. 112: 617-623.

109. Smyth JF, Bowman A, Perren T, Wilkinson P, Prescott RJ, et al. (1997) Glutathione reduces the toxicity and improves quality of life of women diagnosed with ovarian cancer treated with cisplatin: results of a double-blind, randomized trial. Ann Oncol 8(6): 569-573.

110. Leon Schlossberg, George DZ (1997) The Johns Hopkins Atlas of Human Functional Anatomy. Johns Hopkins University, School of Medicine, Maryland.

111. Robert O Young, Shelley Redford Young, LMT (2010) The pH Miracle revised and updated. Hachett Publishing, Boston, USA.

112. Robert O Young, Shelley Redford Young, LMT 2015 The pH Miracle for Cancer. Hikari Omni Publishing, Valley Center, California, USA.

113. Morgan G, Ward R, Barton M (2004) The contribution of cytotoxic chemotherapy to 5-year survival in adult malignancies. Clin Oncol (R Coll Radiol) 16(8): 549-560.

114. Galina Migalko, Universal Medical Imaging Group, Valley Village, California, USA

115. National Institute of Health.

116. Robert O Young, Shelley Redford Young LMT, Matt Traverso (2014) Reverse Cancer Now. Hikari Omni Publishing, Valley Center, California, USA.

117. Burton M, Attura, BElla T Attura, Ole Siggard-Andersen (1995) Reference Studies: Niels Fough-Anderson. Clinical Chemistry 41(10): 1522-1525.

118. Gilariyi M, Bcriyi C, Fekete J, Ikreriyi K, Kovach AGB (1988) Ion Concentration in Subcutaneous Interstitial Fluid Measured versus Expected Values. AM J of Physiolol 255(3 Pt 2): F513-F519.

119. Loughmiller JA, Spire MF, Dritz SS, Fenwick BW, Hosni MH, et al. (2001) Relationship between mean body surface temperature measured by use of infrared thermography and ambient temperature in clinically normal pigs and pigs inoculated with Actinobacillus pleuropneumoniae. Am J Vet Res 62(5): 676-681.
120. Kolb TM, Lichy J, Newhouse JH (2002) Comparison of the Performance of Screening Mammography, Physical Examination, and Breast US and Evaluation of Factors that Influence Them: An Analysis of 27,825 Patient Evaluations. Radiology 225(1): 165-175.

121. From 222 E 68th St, New York, NY 10021 (T.M.K., J.L.) and Department of Radiology, Columbia-Presbyterian Medical Center, New York, NY (T.M.K., J.H.N.). From the 1998 RSNA scientific assembly. Received October 11, 2001; revision requested December 5; final revision received April 11, 2002; accepted April 18. Address correspondence to T.M.K. (e-mail: tkolb@panix. com).

122. Gotzsche PC, Olsen O (2000) Is Screening for Breast Cancer with Mammography Justifiable? Lancet 355(9198): 129-134.

123. Gotzsche PC, Olsen O (2001) Cochrane Review on Screening for Breast Cancer with Mammography. Lancet 358(9290): 1340-1342.

124. Derenzini M, Sirri V, Trerè D, Ochs RL (1995) The quantity of nucleolar proteins nucleolin and protein B23 is related to cell doubling time in human cancer cells. Lab Invest 73(4): 497-502.

125. Journal Article, Research Support, Non-U.S. Gov't, Research Support, U.S. Gov't,

126. Ariosto SS, Jose AY, Robert JG, Robert AG (2009) The Potential Role of Systemic Buffers in Reducing Intratumoral Extracellular $\mathrm{pH}$ and Acid-Mediated Invasion doi: 10.1158/0008-5472.

127. Laboratório de Biologia Molecular, Centro Infantil Boldrini, Campinas, Sao Paulo, Brazil and 2Departments of Radiology and Integrative Mathematical Oncology, Moffitt Cancer Center, Tampa, Florida

128. Requests for reprints: Robert A. Gatenby, Department of Radiology, Moffitt Cancer Center, 12902 Magnolia Drive, Tampa, FL 33612. Phone: 813-745-2843; Fax: 813-745-6070; E-mail:Robert. Gatenby@moffitt.org.

129. Robert 0 Young, Shelley Redford Young (1999) Sick and Tired Reclaim Your Inner Terrain. Woodland Publishing, Orem, Utah.

130. Robert O Young (1999) Pathological Blood Coagualtion. Hikari Omni Publishing, Valley Center, California.

131. HAWK BO, THOMA GE, INKLEY JJ (1951) An Evaluation of the Bolen Test as a Screening Test for Malignancy. Cancer Res 11(3): 157-160.

132. Robey IF, Baggett BK, Kirkpatrick ND, Roe DJ, Dosescu J, et al. (2009) Bicarbonate increases tumor $\mathrm{pH}$ and inhibits spontaneous metastases. Cancer Res 69(6): 2260-2268. 